\title{
Learning Outside the Classroom: A Distinctive Approach to Co- Curricular Recognition in the Australian context
}

\author{
Kylie Austin, Amy Thompson, Julia Coyle, Joe F. Chicharo \\ University of Wollongong, Australia.
}

\begin{abstract}
Co-curricular engagement is an essential part of the student experience in Australian higher education institutions. Whilst there is wide acknowledgement of the benefits of students participating in co-curricular activities, formally recognising students for the knowledge, skills and experiences that they have gained through co-curricular learning has only recently emerged in the Australian context. This practice paper will describe one Australian university's approach in developing and implementing a cocurricular recognition framework. UOWx sits at the core of University of Wollongong's (UOW) student experience, providing holistic and transformational personal development of students. The distinctive features of UOW's approach include developing a whole of institution approach; embedding the student voice into continuous improvement cycles; and developing an active strategy to embed UOWx with employers and community organisations. This approach has transformed student co-curricular learning at UOW, by increasing the breadth of student engagement and deepening student understanding of the knowledge, skills and experiences students have gained through their co-curricular engagement.
\end{abstract}

Keywords: Co-curricular framework; designing co-curricular recognition; reflection. 


\section{Background}

Student engagement in co-curricular activities outside of their formal university degree has been widely valued by Australian higher education institutions. Student engagement in activities, such as mentoring or leadership, have been designed in Australian higher education institutions as part of a holistic approach to the student experience, whereby student learning outside the classroom complements the academic curriculum (Kift, Nelson \& Clarke, 2010). The benefits of students participating in co-curricular activities have been extensively demonstrated in the literature. Tinto (1987) identifies that co-curricular activities contribute to facilitating peer to peer interactions, leading to a smoother transition for students into the higher education setting. Others have emphasised the role that co-curricular activities have played in increasing the likelihood of students completing their degrees (Maher \& Macallister, 2013). Whilst there are institutional benefits in offering co-curricular activities, the literature has also focused on the development opportunities that this provides for students in developing their graduate employability skills (O'Shea, 2019) and sense of active citizenship at a local and global level (Denson \& Bowman, 2013). Despite the extensive literature available that highlights the role and benefits of co-curricular engagement in Australian higher education institutions, there is limited research undertaken in exploring the impact of formally recognising student engagement in these activities (Skalicky \& Caney, 2010). Co-curricular recognition is the formal endorsement of knowledge and skills that students have gained throughout their university degree. In a study of co-curricular recognition in Canadian universities, Elias \& Drea (2013) formed the following definition:

"The Co-Curricular Record (CCR) is a multi-faceted program, which in its broadest sense, both encourages and incentivises engagement. At its core, the $C C R$ is intended to enhance students' learning and development, encourage the discovery and reflection of self-awareness, and foster an environment that encourages civic responsibility and engagement" (pg. 2).

Underpinning this definition are three key principles that Elias \& Drea (2013) identify as needing to be adopted in order for an initiative to be defined as 'co-curricular recognition'. These include: (1) defining co-curricular recognition within an institutional context and making this accessible to students through a central platform to incentivise engagement; (2) experience must be connected through learning and underpinned by a reflective framework; and (3) an institution must formally recognise student engagement through official documentation.

More recent work reflects an increasing focus on students graduating with job-ready skills (STARS 2020). In the competitive Australian graduate market, student engagement in cocurricular activities has been demonstrated to increase student's attractiveness to employers, as they have developed 'broadening' skills, such as critical thinking and emotional 
intelligence, that employers are looking for (O'Shea, 2019). Elias (2014) argues that formal recognition tools can bridge the gap between students and potential employers in articulating the competencies gained through co-curricular engagement. This practice paper will explore the design and implementation of a co-curricular recognition framework at the University of Wollongong (UOW) in Australia. It will provide an overview of the distinctive design principles of UOW's co-curricular recognition framework and provide insights into the impact on student learning.

\section{UOW's approach to Co-Curricular Recognition}

UOW is a research-intensive medium sized university (32,953 enrolments in 2019) with a sharp focus on offering students a personalised and supportive learning experience and in developing exceptional graduates who are highly sought after in the workplace. UOW has a large geographical footprint with campuses located on the south coast of Australia, in Wollongong, Batemans Bay, Bega, Shoalhaven, Southern Highlands, Southern Sydney, the Sydney CBD and South Western Sydney, as well as a network of offshore campuses located in Dubai, Malaysia, Singapore, Hong Kong and China. UOW's domestic student cohort is diverse with $48 \%$ of students the first in their family to attend university, $2.22 \%$ of students are Aboriginal and/or Torres Strait Islander and $29.1 \%$ of students come from a regional, rural or remote area of Australia. Whilst UOW has made a strategic commitment to the progression of UOW students into, through and beyond higher education across the region, this has had to be contextualised in order to leverage the knowledge, skills and experiences that a diverse student cohort brings to UOW.

Underpinned by student experience literature (Tinto, 1987), career development learning (Law \& Watts, 2003) and reflective learning (Stirling \& Kerr, 2015), UOWx was launched in 2015. UOWx was developed as a co-curricular framework that recognised the active contribution students are making to the University, local community, and their own personal and professional development. Led by the UOW Senior Executive and a dedicated Project Manager, three years was spent, prior to the launch, on developing the Co-Curricular Recognition Framework through iterative rounds of consultation with staff, students and industry. UOWx provides students with two formal documents upon graduation:

- UOWx Record: A co-curricular record outlining the activities that a student has engaged with outside of their academic studies; and

- UOWx Award: The UOWx Award recognises students who have demonstrated significant engagement in co-curricular activities.

UOWx is firmly positioned in UOW's Strategic Plan 2020-2025 and 2030 vision, with the aim of recognising transformative learning experiences for students outside of the formal curricula, contributing to UOW's goal of developing graduates who are 21 st Century 
learners. UOWx is distinctively positioned across the Australian university sector, as it provides a framework for existing co-curricular activities and cultivates new learning opportunities at UOW that promote personal and professional development, as well as active citizenship. Examples of these activities include Club \& Society Presidents, Peer Mentors or or Cultural Ambassadors. UOWx provides students with formal recognition of these cocurricular experiences which translates the knowledge and skills gained from these opportunities to the community and graduate employment market.

\section{Design Principles of UOWx}

UOWx aims to facilitate and recognise transformational learning experiences for UOW students outside of the formal curricula through three distinctive design principles outlined in the following sections.

\subsection{An overarching inclusive framework for Co-Curricular Recognition}

UOWx is distinctive within the sector as it is underpinned by an overarching and inclusive framework for co-curricular recognition. This approach leverages the valuable learning opportunities already on offer at UOW, as well as embedding the processes associated with UOWx across the university.

At the core of all UOWx recognised activities, is the UOWx Activity Eligibility Framework. In order to meet the UOWx Activity Eligibility Framework all activities must provide students with initial training and ongoing professional development, as well as enhancing student learning in three or more of the learning streams identified by industry, including leadership; mentoring and wellbeing; community and social change; innovation and creativity; global and cultural awareness; and/or collaboration and communication. Activity Coordinators identify the key learning outcomes that underpin each learning stream, which are assessed and attributed to a learning stream by the UOWx Steering Committee. As can be seen in figure 1, 257 activities across UOW have been recognised by UOWx, enabling students to access a wide variety of opportunities to develop a diverse skill set.

\begin{tabular}{|cccccc|}
500 & 25 & 83 & 178 & 236 & 257 \\
0 & $\frac{25}{2015}$ & 2016 & 2017 & 2018 & 2019 \\
\hline
\end{tabular}

Figure 1: Number of co-curricular activities recognised by UOWx from 2015-2019

Students have commented on the benefit of such an approach, with an Alumni of UOWx describing that "...the diversity in the activities available has enabled me to work on my 
weaknesses, develop my strengths, and has taught me how to become more adaptable and versatile in different environments" (UOWx Alumni surveyed in 2017).

UOWx has been positioned as part of the fabric of the institution due to senior leadership support and embedded systems. The UOWx Co-Curricular Recognition Framework is embedded across the university, with UOW Council-endorsed policies and procedures that guide the implementation of the program across all faculties and departments. Embedded systems allow for UOWx to be delivered at scale and included within UOW's formal suite of graduation documents. Many other universities across Australia and New Zealand use manual processes to produce their recognition documents, however UOW has developed a systems solution which allows students to log their co-curricular activity in the university's learning management system (Moodle), which is integrated with the student management platform (SMP). Formal document issuance of the UOWx Record and UOWx Award are issued alongside UOW's suite of graduation documents which is recorded on students' Australian Higher Education Graduation Statement (AHEGS).

\subsection{Embedding the student voice into continuous improvement cycles}

UOWx has been purposeful in its design in embedding the student voice within its quality review cycle. This approach "is a way of thinking and practicing in higher education that re-positions students and staff as active collaborators in the diverse processes of teaching and learning - empowering students to be actively engaged in, and share the responsibility for, their own education" (Mercer-Mapstone \& Marie, 2017, p. 7). When students are valued and engaged as active collaborators on projects related to teaching and learning there are positive impacts on learning, and an increased sense of leadership in, responsibility for, and motivation around the learning

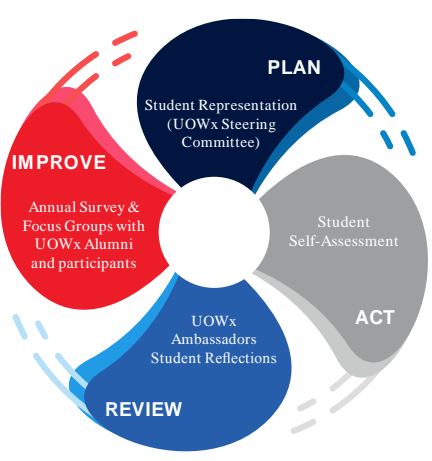

Figure 2: Student voice embedded in continuous improvement cycles. process (Mercer-Mapstone et al. 2017). As such, the student voice is strongly featured in the four stages of the quality review cycle as demonstrated by Figure 2. This includes ensuring student representation on UOWx governance committees; opportunities for self-assessment through UOWx; engagement of students as ambassadors who feed into continuous improvement cycles; and formative surveys and focus groups with UOWx participants, Alumni and activity coordinators.

\subsection{An active strategy that aims to embed $U O W x$ with employers}

Finally, UOWx has an active strategy that aims to embed UOWx with employers. The strategy was developed to competitively position graduating UOW students in the 
recruitment market by enhancing their capacity to articulate the knowledge and skills that they have gained in co-curricular activities during their degree, and ensure that UOWx Record and UOWx Award documents are actively recognised by employers. The strategy is supported by five goals including: developing an integrated communications strategy to raise awareness of UOWx with industry; reviewing the content of the UOWx Record and UOWx Award to better position students to articulate the knowledge and skills that they have learnt outside of the formal curricula to employers; placing a stronger emphasis on co-curricular learning outcomes and reflections; collaboratively developing a suite of opportunities to build student engagement with industry and employers; and regularly reviewing the knowledge and skills that employers value to ensure the currency of the UOWx Co-Curricular Framework.

To date over 100 employers and 8 community organisations have engaged with UOWx. In addition to engaging with networking events and community volunteering placements, industry professionals have provided ongoing mentoring to 129 UOWx student graduates. Through an annual survey of UOWx Alumni, 76\% have said that their co-curricular experiences have helped them stand out to employers and $98 \%$ have said they feel they can effectively articulate their co-curricular experiences to employers. Students have identified that they are "...motivated to receive the UOWx Award to show future employers" (UOWx Alumni, 2020). Also for many students a “...key reason [he] decided to become involved in a range of extra-curricular activities included the opportunity to increase [his] skills...to become more employable" (UOWx Alumni, 2020). Employers also describe the benefits of engaging with UOWx, with one employer stating:

"It's a great initiative and it adds real insight into the mindset and personal traits of the graduating students, something that can be difficult to gain when reading a standard resume or job application." - Illawarra Employer 2015

\section{Transforming Students' Engagement}

Student involvement with co-curricular activities has been transformed by the introduction of UOWx, in terms of the level of their engagement with co-curricular recognition and the development of self-reflection and self-awareness.

\subsection{Student engagement with co-curricular recognition}

UOWx currently has 3310 students logging their co-curricular involvement each year. The initiative has experienced significant growth since 2015 in terms of both student engagement, as well as the numbers of students graduating with the UOWx Record and UOWx Award (see fig 3). 


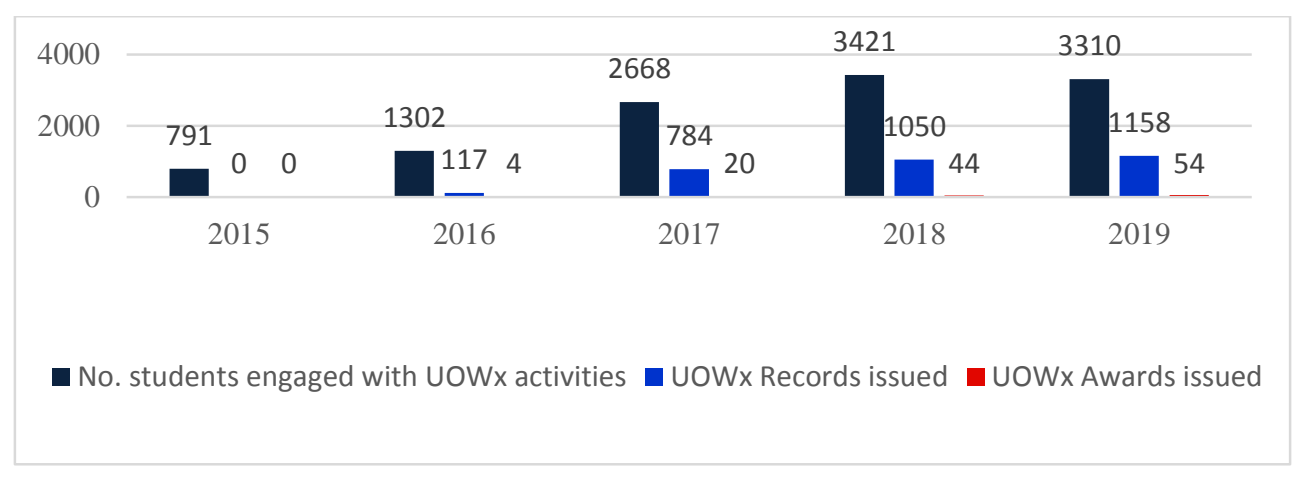

Figure 3: Student engagement in UOWx from 2015-2019

Since 2015, a total of 9981 unique students have engaged with co-curricular activities. Of this cohort, over $30 \%$ of students engage and record more than one co-curricular activity. Current participants describe the incentive to become more involved and the benefits that this offers them,

"I absolutely love UOWx opportunities and I am heavily appreciative of them. ...Also, once I get involved in one, it seems as though all of these other doors open and I am always asked to complete more programs..." (UOWx Student Participant surveyed in 2017).

A particular success of the program is its ability to cater to diverse cohorts of students who typically do not engage in co-curricular activities. The significant work and family commitments experienced by students from divese backgrounds leaves less time for cocurricular activities, despite such experiences being critical for post-higher education employability (O'Shea, 2019). Ensuring that co-curricular participation is achievable for all students has been a key focus for UOWx with targeted approaches to encourage and increase the participation of these target groups implemented.

\begin{tabular}{|l|l|l|l|l|l|}
\hline Student Group & $\mathbf{2 0 1 5}$ & $\mathbf{2 0 1 6}$ & $\mathbf{2 0 1 7}$ & $\mathbf{2 0 1 8}$ & $\mathbf{2 0 1 9}$ \\
\hline International Students & & & & & \\
\hline First in Family Students & $24.27 \%$ & $27.66 \%$ & $35.04 \%$ & $31.83 \%$ & $38.12 \%$ \\
\hline Aboriginal and/or Torres Strait Islander Students & $47.53 \%$ & $46.96 \%$ & $49.40 \%$ & $48.48 \%$ & $44.23 \%$ \\
\hline Students with a Disability & $9.99 \%$ & $8.80 \%$ & $9.35 \%$ & $10.32 \%$ & $10.55 \%$ \\
\hline
\end{tabular}

Figure 4: Equity and international student engagement in UOWx 
Targeted approaches for these student groups include;

- Place-based approaches which provide contextualised face-to-face and digital opportunities for regional and metropolitan students;

- Internal partnerships with Woolyungah Indigenous Centre to embed Aboriginal knowledges into the delivery of co-curricular activities, as well as internal partnerships with accommodation services to engage with regional and international students;

- Recognition of paid as well as voluntary activities so that students can participate in ways that support their diverse situations and needs; and

- Equity scholarships that compensate students who are experiencing financial hardship to enable them to participate in unpaid co-curricular activities.

\subsection{Transforming student engagement through self-reflection and self-awareness}

UOWx is underpinned by a reflective framework (Stirling \& Kerr, 2015) to ensure that all UOWx recognised activities significantly contribute to student learning. Wienhausen and Elias (2017) identify that students have difficulty in promoting their co-curricular involvement to employers. Reflection and self-awareness are critical to student learning and development as part of UOWx and students have the opportunity to formatively reflect on what they have learnt after each engagement through the UOWx Learning Streams and a summative reflection is captured upon completion of the UOWx Award program. Many students reflect on their transformation with UOWx, with one student describing that,

"Throughout more than two years of mingling amongst proactive people, the UOWx experience has had meaningful impact on my personal growth. I became more active and have discovered more about myself and more importantly, I know what I want to do in the future. I am so excited to see how far I can go and how much I can improve in the future" (UOWx Alumni surveyed in 2017).

\section{Conclusion}

This practice paper describes one Australian university's approach in developing and implementing a co-curricular recognition framework. UOWx is a program designed to maximise student engagement in co-curricular learning opportunities with the specific context and student cohort of UOW in mind. UOWx is distinctive in that it provides a framework for existing co-curricular activities and cultivates new learning opportunities at UOW that promote personal and professional development, as well as active citizenship. UOWx provides students with formal recognition of these co-curricular experiences which translates the knowledge and skills gained from these opportunities to the community and 
graduate employment market. Employers and community organisations have engaged strongly with UOWx, with over 100 organisations actively participating and recognizing the value of UOW's co-curricular framework.

\section{References}

Denson, N. \& Bowman, N. (2013). 'University diversity and preparation for a global society: The role of diversity in shaping intergroup attitudes and civic outcomes, Studies in Higher Education, 8(22).

Elias, K. (2014). Employer Perceptions of Co-Curricular Engagement and the Co-Curricular Record in the Hiring Process. University of Toronto, Ontario.

Elias, K. \& Drea, C. (2013). 'The Co-Curricular Record: Enhancing a Postsecondary Education', College Quarterly, 16(1).

Kift, S., Nelson, K. \& Clarke, J. (2010). Transition Pedagogy: A third generation approach to FYE - A case study of policy and practice for the higher education sector. The International Journal of the First Year in Higher Education, 1(1), 1-20.

Law, B. \& Watts, A. (2003). The DOTS Analysis: Original version. Retrieved from http://hihohiho.com/memory/cafdots.pdf

Maher, M. \& Macallister, H. (2013). Retention and attrition of students in higher education: Challenges in modern times to what works. Higher Education Studies, 3 (2), 62-73.

Mercer-Mapstone, L, \& Marie, J. (2017). Practical Guide: Scaling up student-staff partnerships in higher education. Institute for Academic Development: University of Edinburgh.

O'Shea, S. (2019). 'Mind the Gap!' Exploring the post-graduation outcomes and employment of individuals who are first in their family to complete a university degree. NCSEHE, Curtin University.

Skalicky, J. \& Caney, A. (2010). 'PASS Student Leader and Mentor Roles: A Tertiary Leadership Pathway', Journal of Peer Learning, 3, 24-37.

STARS (2019). Co-Curricular Recognition Network. Retreived on $18^{\text {th }}$ January, 2020 at https://cocurricularrecognitionnetwork.com/

Stirling, AE, \& Kerr, GA 2015 'Creating Meaningful Co-Curricular Experiences in Higher Education', Journal of Education \& Social Policy, 2(6).

Tinto, V. (1987). Leaving College: Rethinking the causes and cures of student attrition. Chicago, University of Chicago Press.

Wienhausen, G. \& Elias, K. (2017). 'Beyond the Transcript: The Need to Showcase More'. Change: The Magazine of Higher Learning, 49(4), 14-19. 